\title{
The Role of the Media in the Spiritual and Moral Evolution of Society
}

Lyutsiya Mugtabarovna Gaisina

Irina Mikhaylovna Mikhaylovskaya

Ufa State Petroleum Technological University, Russia, Republic of Bashkortostan, 450062, Ufa, Kosmonavtov Str., 1

Nursafa Gafurovna Khairullina

Tyumen State Oil and Gas University, Volodarskiy Str., 38, Tyumen, 625000, Russia

Oksana Vyacheslavovna Ustinova

Tyumen State University of Architecture and Civil Engineering, Lunacharskiy Str., 2, Tyumen, 625001, Russia

\section{Elvira Venerovna Shakirova}

Irkutsk National Research Technical University, Lermontov Str., 83, Irkutsk, 664074, Russia

\author{
Doi:10.5901/mjss.2015.v6n5s2p93
}

\section{Abstract}

The transition to a progressive information society does not exclude that the media can become the dominant agent of socialization. All the more so important attribute information society stands the so-called "information awareness", which is a product of the growing information and lies at the heart of the global information space. The article presents the results of sociological research on the role of the media in the spiritual and moral development of modern society. The authors conclude that traditional values such as family, faith, work, and mutual respect are the majority of respondents to the second plan, which indicates the "impoverishment" of spiritual principles in the development of modern society. Values such as work, tolerance, responsibility and marriage negatively perceived by respondents. The most significant role in the devaluation of the spiritual and moral development of society play media, the power of influence which is commensurate with the institution of the family and educational impact.

Keywords: society, spiritual and moral development of society, values, socialization, media

\section{Introduction}

Numerous studies of foreign and Russian scientists argue that the spiritual and moral development of society is directly dependent on the process of socialization, which tools-training, education and training - may have a different impact on the individual (De Smaele, 2007; Holz and Wright, 1979; Lehmann, 2011). It depends on who is an agent of socialization: family and inner circle, school, church, community, media. These agents characteristic way for them to mediate the impact on individuals of many factors of social space, transforming them so that society or a particular individual is qualified by this factor as required.

It is obvious that the person in the social space, as well as society as a whole, is in the sphere of influence of several agents of socialization, the extent and nature of the impact of which is determined by many factors: age, social status, social roles of the individual, the number and strength of social ties, education and etc. (Wuthnow, 1998). As rightly pointed L.G. Isaeva, "personality - is the ultimate social education whose support is subject to the laws and the public, while at the same time has a certain freedom of choice. The process of becoming a person is determined by society social norms of behavior, communication and activities in connection with which it can be regarded as a battery socially significant information" (Isaeva, 2005). On the other hand, the formation of personality is inextricably linked with the spiritual culture of society, part of the inherent nature of the personality" (Ustinova and Khairullina, 2014; Gaisina, $2010,2015)$. Therefore, an important role in the process of socialization play traditions and customs, accepted in society. Thus, traditional societies characterized by a high level of influence and authority of the family and the clergy, while the 
more progressive society put at the center of enlightenment, awareness, extrapolation of lessons learned for the benefit of the formation of individual beliefs and attitudes underlying the identity of society (Ustinova, 2014).

One can not disagree with the fact that the spiritual and moral principles are largely shaped in the family and in the process of education, which, according to L.N. Kogan, is an independent social institution and at the same time is a special kind of human activities on the acquisition of knowledge and skills to build their own personality (Kogan, 1992). However, "today the educational role of the school is limited by the small range of features that it has, in contrast to other, much stronger "educational" impact that the young man the media" (Dmitry Archbishop of Tobolsk and Tyumen, 2008). The role of the family is also rethinking falls down on the background of the growing generation gap, its educational function becomes less straightforward. As rightly noted, S.D. Mezencev and A.S. Agavelyan, "the gap between the older and younger generations leads to a decline in the authority of the family, changing perceptions of the moral, social Examples of related groups, which contributes to a significant change in social relations, various negative psychological consequences" (Mezentsev and Agavelyan, 2001).

The authors' agree that of all the agents of socialization is the media are the most influential force. Mass media is becoming a kind of conductor of an open society, an idea developed English sociologist Karl Popper, who proved that the transformation vector of social development is shifting from strict regulation of all spheres and aspects of human life (closed society), to a society that carry the path disclosure of individual features personality (open society) (Popper, 1992). It is the media play a leading role in the observed transformation process (Thompson and Sharma, 1998).

Can not be excluded from consideration, and the fact that the question of socialization should be conducted in respect of mainly younger generation, as older generations often exhibit inertia and conservatism in the views (Sadykova, 2010; Khairullina and Sadykova, 2014). Recognizing inadmissible isolationism in the process of spiritual and moral development of society in the modern world can not rely solely on cultural heritage, traditions and customs, as existing dogmas, rules and regulations sooner or later face in the mind of the individual with the "alternative" reality offered by media. So, at the end of the first decade of the XXI century social networks have provided the so-called shock modernization of traditional societies, for which cultural heritage is rapidly lost its importance.

The impact of the media on the spiritual and moral development, inter alia, has a negative connotation due to one very remarkable circumstance. Progressive ideals of the information society does not exclude the possibility that the media can become the dominant agent of socialization, especially as an important attribute of the information society serves the so-called "information consciousness" (Martin, 1990), which is a product of the growing information and lies at the heart of the global information space (Novikova, 2009). Assuming it could pursue a common policy to build educational and educational models, to develop best practices and real-time access to cultural heritage and other carriers of spiritual and moral ideals. But we can not agree with the statement of the French sociologist A. Mohl, stating that "as a result of the increasing role of the media are still more or less a complete system of knowledge and values is replaced by a set of changeable settings that are constantly affected by the mass media" (Mol, 1993). It is unnecessary variability and pluralism do not allow to recognize the role of the media a valid agent of spiritual and moral socialization of society. However, the mass media are not deprived in any character use the dissemination of knowledge, which, according to the view of M. Castells, is the main source of productivity and defines the so-called the informational mode of social development, which, thanks to new technological conditions that arise in a given historical period, generation, processing and transmission of infrmation have become fundamental sources of productivity and power (Castells, 2000).

Attention is drawn to the position of research on the functions and purpose of the media as a social institution. The authors analysis of domestic and foreign works revealed no negative connotation to the true purpose of the media and communication. Mass media are designed to implement the whole set of functions, which the authors consider it possible to combine into three groups:

1. Traditional media functions: entertainment, information, education, leisure;

2. Private specific functions: socialization, the formation of the spiritual values of the individual activation of intrapersonal factors macro-identity;

3. Socio-specific functions: the formation and propagation of ideology, propaganda of social practices and values, ensuring macro-identity.

Greatest relevance in the current environment is a third group of functions. So, S.I. Bulakh sees as part of the functions of the media "to provide ideological influence on the mood, opinions, evaluations, decisions, and behavior of the masses of people in general and individuals" (Bulakh, 2002). He was echoed N.V. Makhova, which claims that the media are called "change install and maintain the audience to turn them into beliefs shape the internal readiness to perceive or interpret any object or an episode of reality in a certain way" (Makhova, 2004). Presented statements of individual researchers are not a direct indication of the negative contribution of the media in the device is shared by society values, but merely indicates that they are today often act a certain tool for influencing the views of society, the nature of which is 
determined by the application of specific actors.

\section{Methods}

In order to identify the role of the media in the spiritual and moral development of modern society, the authors have conducted surveys of urban residents of the Tyumen region (without autonomous districts). The sample consisted of 264 first survey of men and women 272 (49,3\% and 50,7\%, respectively) (Table 1). The majority of respondents (59,0\%) represented the youth (persons under the age of 35 years).

Table 1. Gender and age structure of the respondents

\begin{tabular}{|c|c|c|c|c|c|c|c|}
\hline \multirow{2}{*}{ Town } & \multicolumn{2}{|l|}{ Men } & \multicolumn{4}{|c|}{ including by age group } & \multirow{2}{*}{$\%$ of total } \\
\hline & $\%$ of the group & all & $18-24$ & $25-35$ & $35-45$ & 45 and over & \\
\hline In all & 100 & 264 & 86 & 73 & 57 & 48 & 49,3 \\
\hline Tyumen & 61,4 & 162 & 57 & 41 & 35 & 29 & 30,2 \\
\hline Tobolsk & 15,9 & 42 & 13 & 12 & 9 & 8 & 7,8 \\
\hline Ishim & 11,7 & 31 & 9 & 10 & 6 & 6 & 5,8 \\
\hline Yalutorovsk & 7,2 & 19 & 5 & 6 & 5 & 3 & 3,5 \\
\hline Zavodoukovsk & 3,8 & 10 & 2 & 4 & 2 & 2 & 1,9 \\
\hline \multirow{2}{*}{ Town } & \multicolumn{2}{|l|}{ Women } & \multicolumn{4}{|c|}{ including by age group } & \multirow{2}{*}{$\%$ of total } \\
\hline & $\%$ of the group & all & $18-24$ & $25-35$ & $35-45$ & 45 and over & \\
\hline In all & 100 & 272 & 82 & 75 & 63 & 52 & 50,7 \\
\hline Tyumen & 64,3 & 175 & 55 & 49 & 36 & 35 & 32,6 \\
\hline Tobolsk & 14,3 & 39 & 10 & 11 & 11 & 7 & 7,3 \\
\hline Ishim & 10,3 & 28 & 8 & 7 & 8 & 5 & 5,2 \\
\hline Yalutorovsk & 6,3 & 17 & 5 & 4 & 5 & 3 & 3,2 \\
\hline Zavodoukovsk & 4,8 & 13 & 4 & 4 & 3 & 2 & 2,4 \\
\hline
\end{tabular}

The geographical distribution of respondents in the sample reflects the structure of the settlement residents of the Tyumen region. Formation of the list of respondents is random on the basis of lists increments, the value of which is determined for each locality in proportion to the total population of people aged 18 years and older. Assessment of the representativeness of the sample was carried out in accordance with the criteria described in Noel: estimated minimum sample size for the population with the required measure of the margin of error and sampling error was calculated on the basis of a comparison of its structure with the structure of the population (Noel, 1993).

\section{Results and Discussion}

\subsection{Results the first stage of the research}

At the first stage of the study respondents were asked questions to establish a hierarchy of values. The results showed that among the absolute value priorities are education (63\%) and health (63\%). However, the leading position of "prosperity" (68,3\%) makes a closer look at the results. Thus, $40,8 \%$ of respondents, the vast majority of which are under the age of 35 years, the highest value postulate "the acquisition of wealth" (Table 2).

Table 2. The distribution of values in life (priority) of the respondents

\begin{tabular}{|l|c|c|c|c|c|c|c|}
\hline \multirow{2}{*}{ Value (priorities) } & \multicolumn{3}{|c|}{ Positive } & \multicolumn{2}{c|}{ Neutral } & \multicolumn{3}{c|}{ Negative } \\
\cline { 2 - 8 } & Rank & Very important & Important & Not very important & Not important & Unacceptable & Rank \\
\hline Have wealth & 1 & 40,8 & 27,5 & 17,4 & 14,2 & 0,0 & 15 \\
\hline Be educated & 2 & 38,6 & 24,4 & 27,5 & 9,5 & 0,0 & 17 \\
\hline To be healthy & 3 & 34,2 & 28,8 & 23,7 & 13,3 & 0,0 & 16 \\
\hline To have children & 4 & 15,5 & 36,4 & 31,3 & 3,8 & 13,0 & 14 \\
\hline Have friends & 5 & 13,9 & 37,7 & 15,2 & 33,2 & 0,0 & 8 \\
\hline Have personal freedom & 6 & 20,3 & 29,4 & 25,6 & 24,7 & 0,0 & 11 \\
\hline
\end{tabular}




\begin{tabular}{|l|c|c|c|c|c|c|c|}
\hline Be respected & 7 & 20,6 & 28,5 & 20,3 & 30,7 & 0,0 & 9 \\
\hline Have a family & 8 & 18,7 & 27,8 & 36,7 & 10,8 & 6,0 & 13 \\
\hline Live by faith & 9 & 11,7 & 25,9 & 21,2 & 41,1 & 0,0 & 6 \\
\hline Gain recognition & 10 & 13,0 & 19,0 & 47,8 & 20,3 & 0,0 & 12 \\
\hline Helping others & 11 & 6,6 & 22,2 & 31,0 & 32,3 & 7,9 & 7 \\
\hline $\begin{array}{l}\text { Receive assistance from others } \\
\text { as necessary }\end{array}$ & 12 & 2,8 & 20,3 & 27,8 & 44,0 & 5,1 & 5 \\
\hline Live work & 13 & 8,9 & 12,3 & 14,9 & 35,8 & 28,2 & 1 \\
\hline To be loved & 14 & 5,1 & 15,5 & 50,3 & 28,2 & 0,9 & 10 \\
\hline $\begin{array}{l}\text { Be tolerant of people of other } \\
\text { faiths }\end{array}$ & 15 & 7,9 & 10,8 & 29,7 & 28,5 & 23,1 & 3 \\
\hline Bear responsibility & 16 & 1,6 & 14,2 & 29,4 & 27,5 & 27,2 & 2 \\
\hline Married & 17 & 5,4 & 6,0 & 38,9 & 19,9 & 29,7 & 4 \\
\hline
\end{tabular}

\subsection{Discussion the first stage of the research}

We can assume that many of these priorities are considered by respondents to be derived from wealth, which to some extent removes the wayside conclusions about the commercialism of the modern Russian society. So, perhaps, education, health, family and children, respect, social status of the individual, etc. put them at the mercy of their own wellbeing.

The obtained results are consistent with findings from other studies. For example, a survey of the population of reproductive age about the hierarchy of their value orientations conducted A.V. Artyukhov in 2012 (Artyukhov, 2012) showed that the value system of the leading positions are occupied by career growth and well-being (see Table 3 ).

Table 3. Distribution of answers to the question of the priority of the value orientations of the individual

(Tyumen region)

\begin{tabular}{|c|c|c|c|c|}
\hline \multirow{3}{*}{ Value orientations } & \multirow{3}{*}{ Rank } & \multirow{3}{*}{ The dominant group } & \multicolumn{2}{|c|}{ Including by } \\
\hline & & & Women & Men \\
\hline & & & \multicolumn{2}{|c|}{ share of mentions this position, \% } \\
\hline Career Opportunities & 1 & $F 25-35$ & 69,0 & 60,8 \\
\hline Material well-being & 2 & M 15-24 & 57,3 & 66,3 \\
\hline Housing & 3 & $F 25-35$ & 49,5 & 48,6 \\
\hline Professional self-realization & 4 & M 15-24 & 34,9 & 56,7 \\
\hline One child & 5 & F 15-24 & 40,3 & 38,8 \\
\hline Strong marriage & 6 & F 15-24 & 51,2 & 24,1 \\
\hline Favorite job & 7 & M 25-35 & 15,1 & 50,2 \\
\hline Personal freedom & 8 & M 15-24 & 19,1 & 40,7 \\
\hline Good health & 9 & MF 25-35 & 29,7 & 33,4 \\
\hline Two children & 10 & F25-35 & 32,1 & 12,3 \\
\hline Public recognition and respect & 11 & M 25-35 & 9,5 & 30,0 \\
\hline Three or more children & 12 & MF 25-35 & 4,4 & 6,1 \\
\hline Percentage to the sample & & - & 54,4 & 45,6 \\
\hline
\end{tabular}

Another, no less interesting study conducted in 2010 V.A. Garabagiy (Garabagiy, 2010), revealed the dominant values of students in Tyumen, among which were: family welfare, interesting and varied work, health (Table 4).

Table 4. Value orientations of students Tyumen universities

\begin{tabular}{|l|c|c|}
\hline Value orientations & Grade point average & Rank by relevance \\
\hline Family well-being & 4,56 & 1 \\
\hline Interesting and varied work & 4,52 & 2 \\
\hline Own health & 4,40 & 3 \\
\hline Have children & 4,27 & 4 \\
\hline Love & 4,06 & 5 \\
\hline Agreement with each other and other people & 3,90 & 6 \\
\hline
\end{tabular}




\begin{tabular}{|l|c|c|}
\hline Personal security & 3,90 & 6 \\
\hline High earnings & 3,84 & 7 \\
\hline Creative work & 3,52 & 8 \\
\hline friends & 3,51 & 9 \\
\hline Stability and respect for traditions & 3,41 & 10 \\
\hline Living and working full risk & 3,25 & 11 \\
\hline Glory and fame & 3,07 & 12 \\
\hline Trouble-free quiet operation & 2,97 & 13 \\
\hline
\end{tabular}

Analyzing the results of the research, it is impossible not to draw attention to the devaluation of a number of human values, such as family, work, mutual responsibility (Mikhaylovskaya and Sultanova, 2014; Shakirova et al., 2014). In most impaired appears the institution of marriage, delivered by respondents to last place in the rankings: only $11,4 \%$ of respondents believe marriage is an important and very important, and 29,7\% - unacceptable. This partly explains this phenomenon as common-law marriage. More and more families are formed spontaneously, without registration state, and just as spontaneously decomposes.

The list of values that have received "negative" assessment leads "work" - 63,9\% of respondents believe career unimportant or unacceptable element of their lives. The authors consider extreme options assessment ("very important" and "unacceptable") as a radical. Thus, the statements of some of the respondents in the spirit of "respect at any cost", "friendship at any cost" more evidence of specific intrapersonal problems of the individual, rather than a deviation in the spiritual and moral development. The same can be said about the negative assessments regarding mutual assistance (in the amount of 13\%).

The results obtained are also interesting from the standpoint of the degree of homogeneity or disunity regional society on the evaluation values (Figure 1).

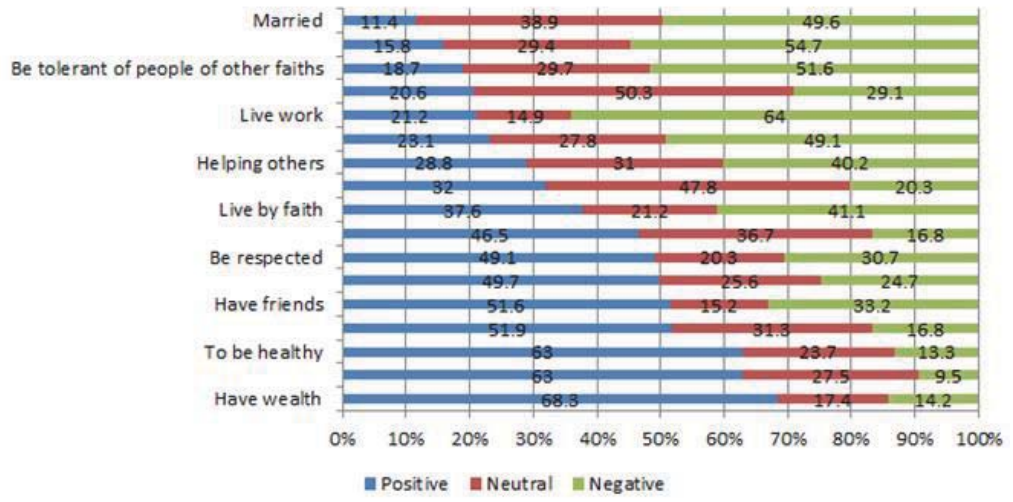

Figure 1. The degree of consolidation of regional society on the evaluation values

Presented in Figure 1 the data can be interpreted as follows: the larger the estimated line compared to the other score, the higher the degree of consolidation of the society in the assessment of the relevant values. Relatively the same size line, reflecting the positive and negative scores indicate equality position, postulating the absence of social consensus on the issue.

In the first phase of the study authors conclude that most respondents are unanimous in their positive assessment of well-being, health, education and child-bearing. Consolidation around negative assessments is observed in relation to the institution of marriage, work, tolerance and responsibility. Also draws the attention of an increasing trend of individualization, which manifests itself in the unwillingness and reluctance to assist her to take. Worried by the fact that almost half the population does not count on help from outside.

\subsection{Results the second stage of the research}

In the second phase of the study evaluated the perception of the respondents of negative social phenomena (lies, 
violence, infidelity, etc.). In particular, the interest was their position on the issue of the admissibility or inadmissibility of these phenomena, and as a result, the readiness to sacrifice moral principles in certain circumstances.

Respondents expressed unanimous in their negative assessment of such a "social disease", as the abandonment of children: there were no one answer is "acceptable" or "more acceptable". At the same time, abortion is acceptable according to almost half of the surveyed women and men (46,3\% and $46,9 \%$, respectively). More than half of men considered acceptable extramarital affairs, smoking, blackmail and threats, selfishness and greed, and women - a minor offense, greed, double standards, adultery, swearing and smoking. Women are not particularly significant in terms of social phenomena the censured extramarital affairs $(70,2 \%)$, selfishness $(67,0 \%)$ and blackmail with threats $(62,1 \%)$.

\subsection{Discussion the second stage of the research}

The results of the survey are consistent with other studies. So, in 2008, the chairman of the Public Chamber of the Russian Federation for Social and Demographic Policy A.V. Ochirova at Parliamentary hearings with reference to the Institute of Sociology, Russian Academy of Sciences led the statistics, according to which "among young people 55\% are willing to step over the moral standards for success. From 30 to $50 \%$ of young people do not consider unacceptable prostitution enrichment at the expense of others, rudeness, drunkenness, bribery, abortion, adultery, public display of hostility towards other nationalities".

Despite the fact that the value of "live by faith" attributed by respondents to ninth place "positive values", about a quarter of those surveyed admit extramarital affairs, the possibility of using threats to achieve their own goals, accept selfishness, greed and bad language.

\subsection{Results the third stage of the research}

At the third stage of the study authors identified factors that have the most significant impact on the value system of the respondents. To do this, the respondents were divided into those with a positive moral and spiritual setting (those who "do not accept the negative social practice" and "people with negative moral and spiritual setting" (all others) (Figure 2).

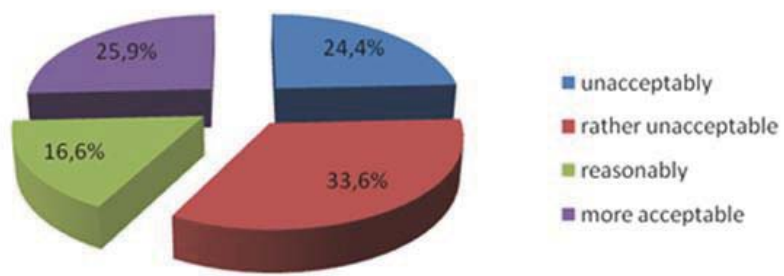

Figure 2. Distribution of respondents to the admissibility of the negative social practices

Respondents with a negative spiritual and moral installing noted as the most important the following factors (Table 5).

Table 5. Distribution of answers to the question about the factors that have the most significant impact on their value system

\begin{tabular}{|c|c|c|c|c|c|c|}
\hline \multirow{3}{*}{ Influencing factors } & \multicolumn{2}{|c|}{ Male / Men } & \multicolumn{2}{|c|}{ Female / Women } & \multicolumn{2}{|r|}{ In all } \\
\hline & all & $\%$ in total & all & $\%$ in total & \multirow{2}{*}{ all } & $\%$ in total \\
\hline & $\%$ of men & Rank & $\%$ of women & Rank & & Rank \\
\hline \multicolumn{7}{|c|}{ Respondents with a positive spiritual and moral installation } \\
\hline \multirow{2}{*}{ So it is accepted in the family } & 59 & 11,0 & 50 & 9,3 & \multirow{2}{*}{109} & 20,3 \\
\hline & 22,3 & 1 & 18,2 & 2 & & 1 \\
\hline \multirow{2}{*}{ The impact of education (school) } & 48 & 9,0 & 53 & 9,9 & \multirow{2}{*}{101} & 18,8 \\
\hline & 18,2 & 2 & 19,3 & 1 & & 2 \\
\hline \multirow{2}{*}{ I live by the canons of religion } & 34 & 6,3 & 42 & 7,8 & \multirow{2}{*}{76} & 14,2 \\
\hline & 12,9 & 3 & 15,3 & 3 & & 3 \\
\hline
\end{tabular}




\begin{tabular}{|c|c|c|c|c|c|c|}
\hline \multirow{2}{*}{ Other options } & 12 & 2,2 & 9 & 1,7 & \multirow{2}{*}{21} & 3,9 \\
\hline & 4,5 & 4 & 3,3 & 4 & & 4 \\
\hline \multicolumn{7}{|c|}{ Respondents with negative moral and spiritual setting } \\
\hline \multirow{2}{*}{ Public opinion, "so all incoming" } & 25 & 4,7 & 21 & 3,9 & \multirow{2}{*}{46} & 8,6 \\
\hline & 9,5 & 2 & 7,7 & 2 & & 2 \\
\hline \multirow{2}{*}{ So it is accepted in the family } & 15 & 2,8 & 16 & 3,0 & \multirow{2}{*}{31} & 5,8 \\
\hline & 5,7 & 4 & 5,8 & 3 & & 3 \\
\hline \multirow{2}{*}{ So do my friends } & 16 & 3,0 & 14 & 2,6 & \multirow{2}{*}{30} & 5,6 \\
\hline & 6,1 & 3 & 5,1 & 4 & & 4 \\
\hline \multirow{2}{*}{ Impose media } & 51 & 9,5 & 63 & 11,8 & \multirow{2}{*}{114} & 21,3 \\
\hline & 19,3 & 1 & 23,0 & 1 & & 1 \\
\hline \multirow{2}{*}{ Other options } & 4 & 0,7 & 6 & 1,1 & \multirow{2}{*}{10} & 1,9 \\
\hline & 1,5 & 5 & 2,2 & 5 & & 5 \\
\hline In all & 264 & & 274 & & 536 & - \\
\hline
\end{tabular}

In the context of the test results of research of intergenerational interactions conducted H.N. Sadykovoy, entrance questionnaire in 2014. The analysis of theoretical material captures the attention of the authors on a variety of forms and mechanisms of intergenerational interaction in all historical periods and the fact that this interaction is determined by the natural-historical factors in the development of society (Sadykova, 2010: pp. 201-203), as well as artificial techniques (in the field of social policy) increase (or decrease) the effectiveness of intergenerational communication (Sadykova, 2014, pp. 124-127).

Assessment of the dynamics of the changes taking place relevant for determining the degree of adaptability of the generational groups to transformations in the economic and social spheres. It is obvious that with age "fading optimism" in estimates from $71,4 \%$ in the young to $28 \%$ in the elderly, which can be explained by differences in the evaluation mechanisms when the older generation compares the current state with the past (the Soviet period) without exposing economy as dominant.

Young correlate same opportunities available to them in Russia and abroad, believing that there have broad prospects for social and professional socialization and purely economic factor, respectively, is for this age group prevail. Inverse proportion to the extreme negative evaluations.

The loss of family values and the importance of family ties - contrived and refutes this study a fact. The unanimity of opinion on mutual support of closely related people found in all age groups within the $55,1-76,5 \%$. And if this interaction for young people expressed more as a material (financial) help, in the older age groups need takes the form of moral and communicative impact, which is why the value of family acquires with age and other content "physical content" through the transformation of "channels" of communication, their the role and importance in the process of life.

The more careful survey results on important and lost values, which, when consolidated gender assessment, a quarter of respondents (23,5 for men and $26,6 \%$ women) indicate the loss of stability of the traditional family with the family itself (as an absolute value) does not take the list of priorities higher position. But "personal happiness in the family" - unconditional leader in the hierarchy of values, but also the loss of this value is fixed a small proportion of respondents (16,7\% and $13,5 \%$, respectively). It should be clarified (adjust) the analytical approach, which requires recognition of the fact that the perception of significance (importance) and relevance (loss) of a particular value is based on not only the static but also the dynamic variables, i.e., understanding the value of each individual in a given generation, due to the complex and often integral factors. In other words, such as "happiness in the family" is defined in the ratio of "l" and "We" and therefore has different motivational and behavioral attitudes as gender and age aspect.

Youth detects an external threat from the ongoing government reforms in the system of education and training under the influence of Western ideology and the political system. The older generation is more "cautious in their opinions", believing that all the proposed options (reasons) are taking place in almost equal measure. However, such reasons as: power held social and economic reforms, Russia's entry into the world community (globalization), changes in the system of education and training, the gap between generations are more gender trim, other - age (generation).

In the wake of the structured opinions of respondents author elaborates system problems due to generation differences. In answering this question is tracked clear polarization in the methodological approach of the respondents, as young "rely" on different value judgments, and the "old" - the difference of life experience and if their first is a formal judgment (static) framework, the latter - into the process (dynamic) - when young people are not "willing to listen and learn". This is a conceptual conclusion as differentiation is found on other aspects and prevailing intergenerational presets do not allow to specify and analyze the true causes of the difficulties in co-generation. Obviously, the problem is indicated in the communicative exchange and difficulties in this area. 
Satisfaction relationships with parents means a majority - unanimously at a certain skepticism of very young (1517 years). Relationship with the older generation (grandparents) demonstrate the degree of dissatisfaction and increase the depth of contradictions especially between the extreme generations. Reverse flow of information - relationship with the children is adequate to the above. In the same vein, and relationships with friends.

Design your own future and that of their country of residence - characteristics that help identify the impact of positive and negative factors for each age group (Generation), which can then be used as a secondary analysis in choice of social development. It must be assumed that the wording of the question itself and the perception of the term "future" of the population is associated with the quality and level of education (development) youth. In this case, the evaluation process is refracted through the perception of their own children.

In general terms, opinion of the respondents coincide, indicating the presence of a single mechanism for interpreting data of the external environment. Thus, according to the majority, will increase Russia's role in the international arena, but the influence of the evolutionary trends of the West will have a significant distorting, leading to rising pragmatism and a widening gap in incomes. Is expected to decrease the values of family and partly because sooner or later, but same-sex marriage will be legalized and it will affect the transformation of the fundamental functions of the family. Also increases the generation gap caused by the increased pace of change. There is also an alarming fact about the radicalization of opinion the youngest of the respondents, where $57,1 \%$. probably objectively reflects the available positive and negative trends in their future positions.

Completely different disparities recorded in the answers to the question of assessment following the current generation. Here generation factor appears clearer it is for positive characteristic: "I believe in them", and the indicator "I sympathize with them". Confidence in their own favorable future declines in every previous generation, which is due rather to the time factor than real and objective reasons. It is obvious that young people who have a whole life ahead have great expectations. But more typical is approximately equal to the percentage of respondents in each age group "not very confident", i.e. the category of the population, which is their own fear "carries" throughout his life.

\subsection{Discussion of the third phase of the study}

These data suggest that the most significant in terms of impact on the spiritual and moral development of society factors are family $(26,1 \%)$, the media $(21,3 \%)$ and school $(18,8 \%)$.

Among respondents with a negative spiritual and moral installing the most important are factors such as the influence of the media $(21,3 \%)$ and public opinion $(8,6 \%)$. It can be assumed that the influence of public opinion in part should be considered as an element of media exposure due to the fact that the latter is a means of broadcasting and distribution of attitudes among social groups.

\section{Conclusion}

In conclusion, the authors make the following conclusions. Among value orientations of respondents Priority is given to the well-being and its derivatives education and health. Traditional values such as family, faith, work, and mutual respect are the majority of respondents to the background, indicating that "impoverishment" of spiritual principles in the development of modern society. In the structure of values shared by individuals, mostly negatively perceived work, tolerance, responsibility and marriage. Also found the institution of marriage and the devaluation of some common cultural components of spirituality and morality, such as faith.

More than half of the respondents consider acceptable such manifestations of lack of spirituality as extramarital affairs, minor offenses, blackmail, selfishness, adultery, swearing, etc. In this case, there is assimilation of double standards characteristic of the society with degraded morality, the manifestation of which is the social stigma of treason against the backdrop of the admissibility of adultery. Company knowingly or under the influence of external forces is undergoing a devaluation of human values and substitution in favor of externally imposed stereotypes.

Revealed unwillingness to help others and get help talking about sampling society. One can not disagree with the fact that spiritual development of society characterized by the synergy and unity, while the absence of the latter is a sign of his spiritual degradation.

The most significant role in imposing negative stereotypes of behavior and to establish a new "scale permitted" media play, the power of influence which is commensurate with the institution of the family and educational impact. For further research in the context of the chosen topic may be of interest to citizens' preferences in the choice of the media, as well as goals accessed. This will reveal the rating of the media on the degree of destructive influence on the spiritual and moral development of society. 


\section{References}

Bulakh, S.I. (2002). Formation of the moral consciousness of the individual cadet college Interior Ministry Media diss. (Master's thesis, Barnaul Law Institute, Barnaul, Russia).

Gaisina, L.M. (2010). Modern social technologies recruitment in Russian oil and gas companies. Bulletin of Bashkir University, 4 (pp.1264-1268).

Gaisina, L.M. (2015). Social technologies as a tool for transformation of personnel management system. The national scientific and political magazine "Power", 4 (pp.155-160).

Dmitry Archbishop of Tobolsk and Tyumen. (2008). Morality as the basis of education. Siberian orthodox newspaper, 10. Retrieved from: http://ihtus.ru/112008/st03.shtml

Isaeva, L.G. (2005). The media as a factor in the formation of the spiritual culture of the Russian society. (Doctoral thesis, Bashkir State Medical University, Ufa, Russia).

Castells, M. (2000). Iformatsionnaya Age: Economy, Society and Culture. (O.I. Shkaratan, Trans.). Moscow, M.: Higher School of Economics.

Kogan, L.N. (1992). Sociology of culture. Yekaterinburg: USU.

Mikhaylovskaya, I.M., Sultanova, E.A. (2014). How to motivate programmer. Proceedings of the international scientific-practical conference: Information Technology. Problems and solutions (pp. 144-146). Ufa, Russia: Eastern Printing.

Martin, W.J. (1990). Information Society. Abstract theory and practice of social and scientific information, 3 (115-123).

Makhova, N.V. (2004). Formation of moral culture of students of the media. (Master's thesis, Moscow State Regional University, Moscow, Russia).

Mezencev, S.D., Agavelyan, A.S. (2001). Family - not just a social unit. Bulletin of Moscow University, 2 (99-102).

Novikova, I.I. (2009). The role and place of media in the development of the information society. Power, 8 (36-39).

Noel, E. (1993). Mass surveys. Introduction to the methodology Demoscopy. (Trans.). Moscow: AVA-Estrie.

Popper, K. (1992). The Open Society and Its Enemiest. Moscow, M.: Phoenix.

Sadykova, H.N. (2010). Interdisciplinary approach to the classification of generations. Bulletin of the Kazan State Technical University A.N. Tupolev, 4 (201-203).

Sadykova, H.N. (2015). Specificity of intergenerational interaction in modern Russia. Modern problems of science and education, 1 (1215).

Ustinova, O.V., Artukhov, A.V. (2012). The influence of value orientations of citizens in their reproductive behavior. Sociology. The Economy. Policy. Proceedings of the higher educational institutions, 4 (56-59).

Ustinova, O.V., Garabazhy, V.A. (2010). Value orientations of students. Bulletin of the Kazan State Technical University A.N. Tupolev, 4 (203-205).

De Smaele, H. (2007). Media and the Information Climate in Russia. Europe-Asia Studies, 8 (1299-1313).

Holz, J.R., Wright, C.R. (1979). Sociology of mass communications, Annual Review of Sociology (Vol. 5. pp. 193-217). Moscow, Russia.

Khairullina, N.G., Sadykova, H.N. (2014) Interaction Between Generations: A Sociological Approach. World Applied Sciences Journal, $31(124-127)$.

Lehmann, C.S. (2011). The Relevance of Spirituality and Reasoned Action for Adolescent Moral and Immoral Behavioral Intentions (Master's thesis, Fuller Theological Seminary, Pasadena, CA 91182, USA). Retrieved from http://gradworks.umi.com/34/86/3 486300.html

Thompson, K., Sharma, A. (1998). Secularization, moral regulation and the mass media. The British Journal of Sociology, 49 (434-455).

Ustinova, O.V. (2014). Deformation of values system as a reason of demographic crisis in Russia. Life Sci J, 11 (465-468).

Ustinova, O.V., Khairullina, N.G. (2014). Family and marriage values devaluation as the reason of decrease in birth rate. Life Sci J, 11 (469-472).

Shakirova, E.V., Eilmsteiner-Saxinger, G., Öfner, E., Gareev, E.S. et al. (2014). Ich bin bereit - Die nachste Generation mobile Fachkrafte in der russischen Erdgas - und Erdolindustrie. Austrian Studies in Social Anthropology, 2 (156-162)

Wuthnow, R. (1998). Morality, spirituality and democracy. Society, 2 (35-43). 